\title{
An Evaluation Procedure for Mutually Exclusive Highway Safety Alternatives under Different Policy Objectives
}

\author{
SnehamayKhasnabis, MASCE ${ }^{1}$, Sabyasachee Mishra ${ }^{2}$, and Chirag Safi $^{3}$
}

\begin{abstract}
The purpose of evaluating mutually exclusive alternatives is to select the one with the highest benefits for implementation. A number of analytic techniques are available for such evaluation purposes. Four such techniques: Cost Effectiveness (C/E), Benefit Cost Ratio (B/C), Internal Rate of Return (IRR), and Pay-off Period (PP) are discussed in this paper, including their theoretical foundation and data requirements, Also discussed are the measures of effectiveness (MOE) associated with each of these techniques, and how these are to be interpreted.

Alternatives to be selected for implementation following such evaluation can typically be funded under different policy objectives. Three such objectives are identified in the paper: Objective A, constrained resource perspective; Objective $\mathrm{B}$, investment perspective; and Objective C, face value perspective. The possible relationship between the alternative selection and program is discussed in the paper. A case study for a set of six mutually exclusive highway safety alternatives is presented using the four analytic techniques and three objectives, resulting in various possible solutions.
\end{abstract}

\footnotetext{
${ }^{1}$ Professor Emeritus, Department of Civil and Environmental Engineering, Wayne State University, 5050 Anthony Wayne Drive, Detroit, MI 48202, Tel: 313.577.3915, Fax: 313.577.3881, Email: skhas@eng.wayne.edu

${ }^{2}$ Research Assistant Professor, National Center for Smart Growth Research and Education, University of Maryland, College Park, MD 20742, Tel: 301.405.9424, Fax: 301.314.5639, Email: mishra@umd.edu

${ }^{3}$ Dowling Associates, Inc., 428 J Street, Ste 500, Sacramento, CA 94533, Phone: (916)266-2190 ext. 307, Fax:

(916)266-2195, Email: csafi@dowlinginc.com
} 
Results show that under compatible assumptions, and for a given policy objective, the outcome of the evaluation is not affected by the choice of the analytic technique. However, for a given analytic technique, the outcome may be affected by the choice of the policy objective chosen. The principles presented are relevant for most public projects (e.g. transit, airports, etc.) involving the investment of taxpayer resources, even though the case study involves a highway safety project.

CE Database subject headings: economic evaluation, policy, mutually exclusive alternatives, highway safety, transit 


\section{Introduction}

The purpose of evaluation of mutually exclusive highway safety alternatives is to ensure that the project selected for implementation is the one with the highest benefits (Boardman et al. 1996).Such evaluation conducted prior to project (pre-project) selection is to be contrasted from post-project analysis, conducted on completion of the project to assess the degree of success of the project in delivering the expected results. The value of post-project analysis is broader, designed to contribute to the knowledge about the ultimate "value" of such projects. The derivation of Crash Reduction Factors or Crash Modification Factors used in highway safety (used in this paper) is based largely upon such knowledge "generated" through post-project analysis (Albert et al. 2005)

Such evaluation conducted prior to project selection is based on the premise that in order for an alternative to be viable, the benefits must exceed the estimated costs (Grant et al. 1990). There may indeed be many alternatives that satisfy the criterion of benefits exceeding cost. The key question is "How to identify the alternative with the highest benefit?" In this paper, the authors attempt to address this seemingly straightforward question, first in general terms, and then for a specific highway safety project.

A number of analytic tools have been developed to aid pre-project evaluation, each with a specific set of characteristics.(USDOT 1991; Mak et al. 1998; Khasnabis et al.2005).A set of four such techniques commonly used for evaluation of highway safety alternatives is discussed in this paper. (NHTSA 1977, Laughland 1975, Jorgenson et al. 1977)

\section{Cost Effectiveness (C/E) Technique}

2. Benefit to Cost (B/C) Ratio Technique 


\section{Internal Rate of Return (IRR) Technique}

\section{Pay Off Period (PP) Technique}

Among other available methods is the Net Present Value (NPV) technique where NPV is the present value of estimated benefits minus costs. Alternatives with positive NPV are to be considered acceptable, and when considering a set of mutually exclusive alternatives, the one with the highest NPV is the one to be selected. Since the use of NPV technique is not as common as that of the other four techniques in engineering applications, NPV is not discussed in this paper. The focus of this paper is on $(B / C), I R R,(C / E)$, and PP techniques, that are indeed derivatives of each other.

Each of these techniques is associated with a specific Measure of Effectiveness (MOE), being $\mathrm{C} / \mathrm{E}, \mathrm{B} / \mathrm{C}$, IRR, and PP respectively. A detailed discussion of these techniques is presented later in this paper. Other relevant questions raised in such evaluation are: "Do the four techniques lead to the same answer”? And, if the answer is “yes”, "Is there a need for a multiple number of techniques? Why would not the B/C technique suffice all needs”? Lastly, there is the seemingly simple question, "Does the project that provides the highest return to the investor, also generate the highest benefit per unit cost”? The authors also address these issues in this paper.

The Measures of Effectiveness (MOE) associated with the four techniques are designed to reflect the degree to which the alternatives being evaluated are expected to meet their economic goals. The C/E technique essentially identifies the project with the least cost per unit benefit, while the $\mathrm{B} / \mathrm{C}$ ratio technique is directed toward designating the project with the highest benefit per unit cost, both at a specified interest rate. The IRR technique attempts to identify the project that provides the highest return to the investor within a specified project life. The PP 
technique on the other hand, helps to identify the project that provides a specified return to the investor in the fastest possible time frame.

\section{Purpose of the Paper}

The purpose of this paper is twofold. First, a discussion is presented on the theoretical basis of the four techniques and the relevance of external factors. These include: the policy objectives under which a specific project is to be funded, availability of data, ease of interpretation, and the intended use of the results. Second, a demonstration of the techniques is presented through a comprehensive highway safety project evaluation.

\section{Policy Objectives}

In this paper, the authors consider three policy objectives:

Objective A (Constrained Resource):

To maximize the number of independent projects to be funded under the program, and to select the optimum project from a set of mutually exclusive alternatives accordingly.

The constrained resource viewpoint is based upon the premise that resources available for public projects are generally far short of those needed to meet the demand; and hence public policies should be directed to support the maximum number of independent projects. Adopting objective A would result in the following ground rule:

"From a set of mutually exclusive alternatives, select the least cost project, with the stipulation that benefits must exceed cost."

Objective B (Investment):

To use an investment viewpoint for selecting the optimum project from a set of mutually exclusive alternatives, and to fetch the highest return to the tax-payer. 
The authors used the "Defender-Challenger" technique (Grant et al. 1990)for this (marginal cost) analysis that requires a pair-wise comparison of alternatives in increasing order of capital cost. Alternatives that cannot be justified through marginal cost analysis are eliminated, and the pair-wise comparison is continued until the most capital-intensive alternative is analyzed. The alternative with the highest capital cost that "qualifies" the marginal cost analysis is to be selected. The use of Objective B would result in the following ground rule: "From a set of mutually exclusive alternatives, select the project that provides the highest return to the investor."

\section{Objective C (Face Value)}

To select the alternative that appears to return the highest amount of benefit per unit cost. Neither investment, nor constrained resources should be a factor; projects should be selected on the basis of the "face-value" of the MOE's. Adopting Objective C would result in the following ground rule:

"From a set of mutually exclusive alternatives, select the project with the highest amount of benefit per unit cost.”

The authors feel that the three policy objectives cover the practical range of funding possibilities of a majority of public projects. Note, the three ground rules can be looked upon as "generic" rules. When associated with a given analytic technique, more "specificity" can be incorporated into the ground rules, resulting in specific decision rules.

\section{The Four Analytic Techniques}

A brief theoretical foundation of the four techniques is presented below to provide continuity with the case study demonstration. The following symbols are used in the discussion. 


\begin{tabular}{|c|c|c|}
\hline Notation & & Explanation \\
\hline$(A)$ & : & Sinking Factor \\
\hline$(A)$ & : & Capital Recovery Factor \\
\hline APOM & : & Annualized Worth of POM \\
\hline$(B)$ & : & Benefit Cost Ratio \\
\hline $\mathrm{C}$ & $:$ & Unit \$ value of each crash prevented \\
\hline$(C)$ & : & Cost Effective Index \\
\hline $\begin{array}{c}(E) \\
E U A B\end{array}$ & : & Equivalent Uniform Annual Benefit \\
\hline EUAC & : & Equivalent Uniform Annual Cost \\
\hline$I$ & : & Initial Cost (\$) \\
\hline$i$ & : & interest rate used (\%,annual) \\
\hline $\operatorname{IRR}$ & : & Internal Rate of Return (\%,annual) \\
\hline K & $:$ & Annual Operating and Maintenance Cost \\
\hline MARR & : & Minimum Attractive Rate of Return \\
\hline$N$ & : & Number of crashes prevented annually \\
\hline$N P W$ & : & Net Present Worth $(\$)=$ PWOB-PWOC \\
\hline$n$ & : & Project Life (years) \\
\hline$n_{1}$ & : & Pay off Period (years) \\
\hline$P$ & $:$ & Present Worth Factor (Uniform Series) \\
\hline$\left(\frac{P}{F}\right)$ & : & Present Worth Factor (Single Payment) \\
\hline$P P$ & : & Pay off Period (years) \\
\hline
\end{tabular}


POM : $\quad$ Periodic Operation and Maintenance

PWOB $\quad$ : $\quad$ Present Worth of Benefit (\$)

PWOC : $\quad$ Present Worth of Cost (\$)

S $\quad$ : Salvage Value (\$)

$y_{1}, y_{2} . . y_{n} \quad: \quad$ Years when periodic O\&M cost is

\section{Cost Effectiveness (C/E) Technique}

The Cost Effectiveness (C/E) technique is based upon the premise that the alternative that costs the least to derive one unit of benefit is considered to be most cost effective. For the highway safety project case, this should be the alternative that costs the least to prevent a highway crash (of a specific type). The algorithm is as follows:

$$
\frac{C}{E}=\frac{E U A C}{N}
$$

where,

$$
E U A C=I\left(\frac{A}{P}\right)+K+P O M\left[\left(\frac{P}{F}\right)_{n=y_{1}}+\left(\frac{P}{F}\right)_{n=y_{2}}+\ldots+\left(\frac{P}{F}\right)_{n=y_{n}}\right]\left(\frac{A}{P}\right)-S\left(\frac{A}{F}\right)
$$

$N=$ Number of crashes prevented annually

$\left(\frac{C}{E}\right)=$ Cost Effective Index (Dollars spent to Prevent Each Crash)

The $(\mathrm{C} / \mathrm{E})$ technique is used when knowledge about the alternative that costs the least to derive one unit of benefit is the desired answer. Because no dollar value is attached to benefits, the $\mathrm{C} / \mathrm{E}$ technique only provides a comparative (as opposed to an absolute) measure of "goodness" of the alternatives being tested, and only the Face Value perspective (objective C) is 
pertinent. Thus, a project designated as the most cost effective, may not necessarily be cost efficient. The advantage of this technique is that, it is not necessary to attach a dollar value to the benefits, a task often considered the most difficult one in evaluating public projects (Mak et al. 2005; USDOT 1991; Winfrey 1974): The decision rule can be summarized as:

\section{Objective C:}

* Select the alternative with the lowest (C/E) Index

\section{Benefit Cost (B/C) Technique}

The $(\mathrm{B} / \mathrm{C})$ ratio is the most common technique used in project evaluation, primarily because of its ease of interpretation (Winfrey 1974; Khasnabis et al. 1999a; Khasnabis et al. 1999b; Harford 2006; Li and Madanu 2009; Rotaris et al. 2010; Holz-Rau and Scheiner 2011). The technique is used when the number of units of benefits derived per unit of cost incurred is the desired answer. The algorithm used is:

$$
\frac{B}{C}=\frac{\text { Benefit }}{\text { Cost }}=\frac{E U A B}{E U A C}
$$

where,

EUAC can be computed as shown in equation 2. The computation of EUAB can be difficult, particularly in public projects (a feature true in all the three techniques, (B/C), (IRR), and (PP), a detailed discussion of which is beyond the scope of this paper. In the specific highway safety project case, $E U A B$ can be computed as:

$$
E U A B=N x C
$$


$\mathrm{N}=$ Number of Crashes (of a particular type) prevented annually

$\mathrm{C}=$ Unit $\$$ value of crashes prevented so that, $\frac{B}{C}=\frac{(N x C)}{E U A C}$

In the evaluation process, all projects with $(\mathrm{B} / \mathrm{C})$ ratios exceeding unity are considered viable. .

These decisions rules can be formalized as:

Objective A:

Select the alternative with the least EUAC, provided $(B / C)_{a b s o l u t e} \geq 1.00$

Objective B:

Select the alternative with the highest investment, subject to

$(B / C)_{a b s o l u t e} \geq 1.00$, and

$(B / C)_{\text {marginal }} \geq 1.00$

Objective C:

Select the alternative with the highest $(B / C)_{a b s o l u t e}$ value subject to $(B / C)_{a b s o l u t e} \geq 1.00$

\section{Internal Rate of Return (IRR) Technique}

The IRR technique is also used widely, when the yield of the investment is the desired answer (Winfrey 1974; Khasnabis et al. 1982; Bonnafous and Jensen 2005; Anguera 2006; Salling and Banister 2009; Khasnabis et al. 2010; Hobday and Knight 2010; Vassallo 2010). IRR is defined as the interest rate at which the Net Present Worth (NPW) or the Net Annual Worth (NAW) of the project equals zero The IRR technique requires the computation of the interest (or the yield) that the project is expected to return to the investor. The algorithm used here is for NAW to keep it consistent with the remainder of the paper: 


$$
\begin{gathered}
\text { SetNAW =0,i.e. } \\
E U A B=E W A C, \text { i.e. } \\
N x C=I\left(\frac{A}{P}\right)+K+P O M\left[\left(\frac{P}{F}\right)_{n=y_{1}}+\left(\frac{P}{F}\right)_{n=y_{2}}+\ldots+\left(\frac{P}{F}\right)_{n=y_{n}}\right]\left(\frac{A}{P}\right)-S\left(\frac{A}{F}\right)
\end{gathered}
$$

A theoretical solution of equation (5) to derive the appropriate interest can be computationally complex. An empirical solution may be attained by systematically altering the interest rate until a convergence is found. However, a range of software packages is currently available to derive a computationally efficient solution.

While the IRR technique does not require the assumption of an interest rate for computational purposes, the assumption of an interest rate (termed as the Minimum Attractive Rate (MARR)), is, nonetheless necessary. MARR is used to judge the attractiveness of proposed investments, and represents a "bench-mark" yield, below which all investment proposals are to be considered unattractive. The determination of MARR is normally a policy issue and criteria for setting it are quite varied (Grant et al. 1990).All projects yielding an IRR exceeding an initially specified Minimum Attractive Rate of Return (MARR) become viable. The decision rules can be formalized as:

\section{Objective A:}

Select the least expensive alternative, provided $I R R_{\text {absolute }} \geq M A R R$

\section{Objective B:}

Select the alternative with the highest investment, subject to

$I R R_{\text {absolute }} \geq M A R R$, and 
$I R R_{\text {marginal }} \geq M A R R$

Objective C:

Select the alternative with the highest $I R R_{\text {absolute, }}$ provided $I R R_{\text {absolute }} \geq M A R R$

\section{Pay Off Period (PP) Technique}

The (PP) technique is used when "the time taken by the project to pay for itself" is the desired answer, and can be looked upon as the conceptual counterpart of the IRR technique. While in the IRR technique, the interest rate is the desired answer, given the project life; in the PP technique, the time period needed to pay off for the project, given an interest rate, is the desired answer. The algorithm used is the same as the one used in the IRR technique (equation 5). An interest rate must be assumed (usually the MARR or higher), and the value of $n_{1}$, (Pay off Period) is sought empirically such that equation (5) is satisfied.

If $n_{1}>n$, alternative is not viable

If $\mathrm{n}_{1} \leq \mathrm{n}$, alternative is viable.

Stated differently, if a project pays for itself earlier than the period the project is expected to last, it essentially provides "free" service to the investor for the extra duration. If on the other hand, it takes longer for the project to pay for itself, the additional period is a "liability" to the investor. All projects with a PP lower than $\mathrm{n}$ are considered viable. The decision rules can be formalized as follows:

\section{Objective A:}

Select the alternative with the least investment, subject to $n_{1} \leq n$

Objective B:

Select the alternative with the highest investment subject to: 
$\left(n_{1}\right)_{\text {absolute }} \leq n$

$\left(n_{1}\right)_{\text {marginal }} \leq n$

Objective C:

Select the alternative with the lowest $\left(n_{1}\right)$ absolute value provided

$\left(n_{1}\right)_{\text {absolute }} \leq n$

Note: The concept of (IRR) marginal and (B/C) marginal is widely used as a decision making tool. However, the concept of marginal Pay off Period, $\left(\mathrm{n}_{1}\right)$ marginal is uncommon, partly because of the Pay off Period technique itself is seldom used as a decision making tool. The interpretation of marginal Pay off Period is the number of years taken by the extra-investment to pay for itself at a specified interest rate. If this Pay off Period exceeds the project life, the extra investment is not justified.

\section{Case Study Demonstration}

The relationship between policy objectives, analytic techniques and evaluation is demonstrated through a case study comprising a total of six mutually exclusive highway safety alternatives. The case study is derived from a recent project conducted by the authors at Wayne State University to develop a toolbox for Michigan Department of Transportation (MDOT) for "Safety Improvements for Urban Arterials” (Khasnabis et al. 2006)

The study site is the intersection at M-97 (Groesbeck Highway) and Metro Parkway, located in Macomb County, Michigan, within the Detroit metropolitan area, with over 80,000 vehicles per day using this intersection. Both M-97 and Metro Parkway are six lane facilities. Metro Parkway is divided by a median. Based upon the analysis of three year crash data, the site experienced approximately 23 injury crashes and 47 Property Damage Only (PDO) crashes per 
year. Expected traffic growth is four percent per year. Other operating features of the intersection are:

- No left turn is allowed on the intersection with Michigan left turns on Metro Parkway.

- Near and far signal heads are in operation for Groesbeck Highway

- Multiple driveway access points exist on Groesbeck Highway

- A pedestrian over bridge exists on the north bound of the intersection

A set of probable causes of the crashes, based upon review of the crash reports and site visits along with the suggested countermeasures are presented in Table 1. Six alternatives are chosen from probable causes and presented in Table 2. Each alternative consists of a set of improvements as derived from probable causes and each improvement is associated with a Crash Reduction Factor (CRF). Annual operating and maintenance costs are assumed to be 10 percent of the initial investment. Expected project life is 10 years, and salvage value is assumed to be zero for all the alternatives. MARR is assumed to be six percent and the same interest rate is assumed in amortizing the investment cost.

The initial investment required for alternatives 1 through 6 are: $\$ 110 \times 10^{3}, \$ 214 \times 10^{3}$, $\$ 258 \times 10^{3}, \$ 444 \times 10^{3}, \$ 694 \times 10^{3}$, and $\$ 916 \times 10^{3}$, respectively. The annual Operating and Maintenance (O\&M) costs and the Periodic O\&M costs (incurred every three years) were assumed to be 10 and 30 percent respectively of the initial costs. Based upon the use of CRF values, and four percent annual traffic growth, the expected numbers of crashes likely to be prevented per year are estimated as12.67, 18.19, 30.69, 30.83, 35.12, and 39.25respectively, for alternatives $1,2,3,4,5$, and 6 .

In computing project benefits, only safety benefits were considered following MDOT practice. Operational and environmental benefits were not considered in the analysis. There is a 
large body of literature on CRF) a detailed discussion of which is beyond the scope of the paper. Briefly, CRF's are derived from post project evaluation for specific countermeasures, and used to estimate the number of crashes likely to be "saved" or "prevented" that are attributable to the countermeasures installed (Council et al. 1980; FHWA 1981a; FHWA 1981b; Datta et al. 1978, Albert et al. 2005). The "worth" of each crash saved is taken from National Safety Council (NSC) is $\$ 7,400$ for PDO and $\$ 49,700$ for Injury crashes (NSC 2004).

The NSC estimates of the average costs of fatal, injury and PDO crashes are used to illustrate their impact on the nation's economy. The costs are a measure of the dollars spent and income not received due to these crashes. The estimates are not a reflection of what people are willing to pay for improved safety. NSC has conducted the necessary theoretical groundwork and empirical valuation of injury costs both under the "willingness to pay" and comprehensive cost concept. NSC suggests that "Estimates of the crash cost are based on the comprehensive cost concept and should be used for cost-benefit analyses wherever feasible.” However, the crash cost estimates are not generally used to include the value of a person's natural desire to live longer or to protect the quality of one's life.

As a part of this demonstration exercise, each of the six alternatives is evaluated by the four techniques under the three policy objectives discussed. While the procedure for Objective A and Objective C are straightforward, for Objective B, the procedure calls for developing two sets of MOE's, i.e. $\mathrm{MOE}_{\text {absolute }}$ and $\mathrm{MOE}_{\text {marginal }}$ for the Defender-Challenger analysis discussed earlier.(Grant et al. 1990). 


\section{(C/E) Technique}

Results of (C/E) technique are presented in Table 3. Row 6 shows the $(\mathrm{C} / \mathrm{E})$ values for each alternative computed using the formulations presented for objective $C$ per earlier discussion. Alternative 3 should be selected as the most cost effective, as the cost of preventing a crash is the minimum for this alternative, being $\$ 2,720$ per crash. The concept of marginal return on the extra investment is not applicable for the $(\mathrm{C} / \mathrm{E})$ technique.

\section{Benefit Cost Ratio (B/C) Technique}

Table 4 shows the results of applying the $(B / C)$ ratio for the six alternatives. The $(B / C)_{\text {absolute }}$ and $(\mathrm{B} / \mathrm{C})_{\text {marginal }}$ figures are shown in lines 6 and 11 respectively. Based upon a review of the data, project selection is as follows:

\section{Objective A:}

Select alternative 1 , as this is the least expensive project with a $(B / C)_{\text {absolute }}$ ratio exceeding unity.

\section{Objective B:}

Select alternative 6, as this is the most expensive project, for which both the $(B / C)_{a b s o l u t e}$ and $(B / C)_{\text {marginal }}$ values exceed unity. It should be noted that during the Defender-Challenger analysis, alternative 4 , with a $(B / C)_{\text {marginal }}$ ratio of 0.08 , is eliminated from further consideration, so that alternative 3 continues as the defender to be challenged by alternative 5 . Further, alternative 6 with a $(B / C)_{\text {marginal }}$ of 2.07 is successful in challenging alternative 5 , and is thus declared the “winner”.

\section{Objective C:}

Select alternative 3 , as the $(B / C)_{\text {absolute }}$ ratio is maximized at 13.21 
Internal Rate of Return (IRR) Technique

Results are presented in Table 5, with the (IRR) absolute $_{\text {and (IRR) }}$ marginal values shown in lines 6 and 9 respectively.

Based upon a review of the data, project selection is as follows:

\section{Objective A:}

Select alternative 1 , being the least expensive alternative with an (IRR) $)_{\text {absolute }}$ exceeding the MARR of six percent.

Objective B:

Select alternative 6, being the most expensive alternative, with both (IRR) $)_{\text {absolute }}$ and (IRR) marginal exceeding six percent

Note that alternative 4, with an (IRR) marginal of less than six percent is eliminated from further consideration, so that alternative 3 continues to be the defender, to be challenged by alternative 5 at the next step. This process results in the alternative 6 as the "winner"

\section{Objective C:}

Select alternative3 that provides the highest (IRR) absolute $_{\text {of } 355.33 \%}$

\section{Pay off Period (PP) Technique}

Results are presented in Table 6, with the (PP) absolute $_{\text {and }}(\mathrm{PP})_{\text {marginal }}$ values shown in lines 5 and 10 respectively. 


\section{Objective A:}

Select alternative 1, as the least expensive alternative, with a $(P P)_{\text {absolute }}$ value less than 10 years Objective B:

Select alternative 6 as the most expensive alternative, with both $(P P)_{\text {absolute }}$ and $(P P)_{\text {marginal }}$ values less than 10 years.

Note that for alternative 4, $(P P)_{\text {marginal }}$ exceeds 10 years, indicating that the alternative will not be able to pay off extra investments during the service life. This process results in the section of alternative 6 as the "winner".

Objective C:

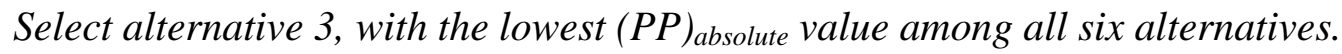

\section{A Special Observation on Policy Objective B}

Under the objective of Investment (B) that attempts to generate the highest return to the investor, the Alternative 6, with a (B/C)absolute ratio of 4.76 (Table 4, row 6) was selected, even though it has the lowest $(\mathrm{B} / \mathrm{C})$ absolute ratio among the six. The key to this selection lies in row 11, that shows the $(\mathrm{B} / \mathrm{C})$ marginal is 2.07 . This selection perfectly matches with the ground-rule cited in page 10 of the paper that essentially prescribes that under objective $B$, the alternative to be selected is the one with the highest investment and with both $(B / C)$ absolute and $(B / C)$ marginal values exceeding unity. Table 4 shows that alternative 6 is the only one that meets this requirement. Table 7 is presented below in an effort to further explain the logic with selected data from Table 4, and some additional data generated using the criterion of Marginal Rate of Return (MRR).

MARR has been defined as the interest rate below which all other yields are to be considered unacceptable. An implied and parallel assumption is that any fund not invested in the proposed 
project will fetch to the investor a return at least equal to the MARR. Because policy objective B represents an investment viewpoint, the above implication of MARR seems immensely justified. The data presented in Table 7 is developed around this parallel assumption.

In Table 7, row 1 shows the Present Worth of Cost (PWOC) of the alternatives including the Annual and Periodic O \& $\mathrm{M}$ costs at $6 \%$ over the 10 year period besides the initial investment, and is calculated as the EUAC (Table 4, row 4) multiplied by (P/A) factor, being 7.36. Row 2 is the PWOC of the un-invested capital for each Alternative, being the difference the PWOC of Alternative 6 (the highest investment Alternative) and the PWOC of the alternative in question, being termed as the "Excess Capital" hereinafter. For example, for Alternative 1, the Excess Capital in row 2 is $\$ 1915.30$, being the difference between $\$ 2176.8$ and \$261.5. All other numbers in row 2 are computed accordingly. For Alternative 6, this amount is zero, because all the available capital is to be invested in the alternative itself. The implication (of the parallel assumption discussed above) is that if the agency were to select in Alternative 1 (for example), it would have an additional amount of \$1915.3 available for investment elsewhere in the market place, that would, at the very minimum, fetch an annual return equaling the MARR for the next 10 years. Row 3 shows this return, being calculated as the amount in row 3 multiplied by the (A/P) or Capital Recovery Factor at $6 \%$ for 10 years $(0.13587$ or the inverse of the (P/A) factor of 7.36). Row 3 shows the amount consistently decreases from Alternative 1 to 2,3,...6. For Alternative 6, this amount is zero, as no Excess Capital is available for this alternative. Row 4 is the annual return for the investment itself, being equal to the EUAB (row 5, Table 4). Row 5 shows the total annual return from each alternative, being the sum of row 3 (return from Excess Capital) and row 4 (Project return). Row 5 shows that the total annual return from the package of $\$ 2176.8$, (being the sum of the PWOC of the alternative and the Excess 
Capital) is maximized for Alternative 6 (being equal to \$1408). This amount directly confirms the selection of Alternative 6 under project objective B. It also shows that the alternative that produces the highest return per unit cost (Alternative 3, Table 4), is not necessarily the alternative that generates the highest return to the investor (Alternative 6, Table 7). (Note: All dollar figures presented in this paragraph are in units of $\$ 1000$ ). The same principle can be demonstrated with the IRR and PP techniques.

\section{Summary of the Results}

Microsoft Excel was used to compute the MOE's of the four analysis techniques presented in Tables 4, 5, and 6. The "Yes" (Y) designation in rows 7, 6, and 7 of these tables (respectively) clearly indicate that all the six alternatives are viable. This discussion does not pertain to Table 3 , as there are no dollar measures associate with benefits by the C/E technique. A summarized version of the ground rules and the analytic techniques is presented in Table 8 , along with the results of the case study results to better explain the selection process.

Table 8 shows that for a given objective, the selection of the project from a set of mutually exclusive alternatives is independent of the analytic technique used. In other words, the choice of the analytic technique does not affect the selection of the project. This table shows that for Objective A, the alternative selected is 1 , and for Objectives $\mathrm{B}$ and $\mathrm{C}$, the alternatives selected are 6 and 3 respectively, independent of the analytic technique.

Table 8 also shows that the selection of the project depends upon the policy objective. For example, the use of the $(B / C)$ ratio technique results in three different solutions, being 1,6 , and 3 for Objectives $\mathrm{A}, \mathrm{B}$, and $\mathrm{C}$ respectively. This is clearly reflected in the fact that in the evaluation matrix (Table 8), the solutions across each column are the same, but different across 
each row. The results underscore the importance of establishing the policy objective at the very outset of the planning process, before actual evaluation is conducted. The analysis clearly shows that under constrained resource scenario (Objective A) alternative 1 should be selected, while the investment viewpoint (Objective B) should lead to the selection of alternative 6. . Under the face value (Objective C), criterion, alternative 3 should be identified as the most desirable solution. These results can be summarized as follows:

1. Select the least cost alternative, (provided benefits exceed costs) if the policy of constrained resource is the ground-rule.

2. Select the most capital- intensive alternative, (provided both the absolute and marginal measures of effectiveness are acceptable), if maximization of total benefits (Investment) is the ground rule.

3. Select the alternative with the highest amount of benefit per unit cost under the Face value ground rule.

The intersection improvements analyzed in the case study can be considered "low cost" projects, particularly in relation to the benefits derived. The NSC figures ("worth" of crash “saved” being $\$ 7,200$ and $\$ 49,700$ for PDO and Injury crashes respectively), (NSC 2004), resulted in extremely high pay-offs, as indicated by the MOE's, such as three digit IRR's and very small Pay-off Periods. The cost data used were derived from various published records, and are considered realistic. The analyses presented clearly show that highway safety improvements are highly cost-effective considering their likely impact on preventing future crashes. 


\section{Conclusions and Recommendations}

The purpose of this paper is to present a broad overview of the different analytic techniques and the role of policy objective for evaluation of mutually exclusive alternatives and to demonstrate the application of the principle with a highway safety project as an example. Four analytic techniques that are commonly used in highway safety evaluation programs are discussed in the context of three policy objectives. Following a discussion of the theoretical basis of the four techniques and the significance of the three objectives, the authors demonstrate their interrelationship through a set of six mutually exclusive highway safety improvement alternatives. The major conclusions of the paper are:

- Under compatible assumptions, and for a given policy objective, the choice of the analytic technique does not affect the outcome of the evaluation. By "compatible assumptions”, the authors imply that all items designated as costs or benefits are assumed to have been done uniformly for all the techniques. The compatibility of assumptions will be violated, if for example, an item treated as a cost in the IRR analysis, is treated as a negative benefit in the $\mathrm{B} / \mathrm{C}$ analysis. The project finally selected is independent of the analytic technique used, given a specific policy objective.

- The choice of the analytic technique should however, be based on the intended use of the results and availability of data. The (C/E) technique should be selected to identify the project with the least cost per unit benefit, and if the analyst is reluctant to attach a dollar value to the benefits derived. The technique has however, a serious limitation. The project selected as the most cost effective, may not necessarily be cost efficient, in that the investment cost may not necessarily be "recovered" by way of the benefits generated. The technique, however, can be used to rank-order the alternatives being evaluated. If the 
amount of benefit derived per unit cost incurred is the desired result, the $(\mathrm{B} / \mathrm{C})$ ratio should be used. If, on the other hand, the return on the investment is the desired answer, the IRR technique should be the desired choice. Lastly, if the analyst's interest is in the time period for the project to pay for itself, the (PP) technique should be used.

- The authors also demonstrate that for a given analytic technique, the outcome of the evaluation may be affected by the choice of the policy objective. In the case study presented, the three objectives resulted in the selection of different alternatives for the same analytic technique. Of the four techniques presented, (B/C) ratio and IRR are used more frequently, primarily because of their ease of interpretation. Also, it can be shown that the $(\mathrm{B} / \mathrm{C})$ ratio computed at the IRR derived will always equal unity, and that the PP, when computed at the IRR derived, will always equal the project life, thereby demonstrating that there is indeed no difference between the three techniques.

The authors recommend that for such evaluation, the policy objective be defined at the outset before economic analysis is conducted. The fact that the choice of the objective may affect the final outcome makes it all the more important, that the policy objective be defined first, and the project selected accordingly. Although the case study deals with highway safety alternatives, the principles presented in this paper are relevant for most public projects that require the most prudent investment of taxpayers' scarce resources. The process of "alternative analysis" is common in all public projects including highways, transit, airports, and other infrastructure development involving public dollars. As in the case presented, the policy objective may significantly affect the outcome of evaluation, and hence the investment of tax-payers resources in public projects. 


\section{Acknowledgement}

The authors greatly appreciate the suggestion from the reviewers and their viewpoints have substantially improved the presentation of the research. The authors are thankful to Michigan Department of Transportation (MDOT) for supporting the study "Safety Improvements for Urban Arterials” in 2005-2006, at Wayne State University (WSU) which served as the foundation of this research. The opinions and viewpoints expressed are entirely those of the authors, and do not necessarily represent policies and programs of the agencies mentioned in the paper. 


\section{References}

Albert, G., Shen, J., and Rodreguez, A. (2005).Update of Florida Crash Reduction Factors and Countermeasures to improve the Development of District Safety Improvement Projects. Final Report: BD015-RPWO-4, State of Florida Department of Transportation.

Anguera, R. (2006). The Channel Tunnel--an ex post economic evaluation. Transportation Research Part A: Policy and Practice, 40(4), p.291-315.

Boardman, A., Greenberg, D.H., Vining, A.R., and Weimer, D. K. (1996).Cost Benefit Analysis: Concepts and Practice, Prentice Hall, New Jersey.

Bonnafous, A., and Jensen, P.(2005). Ranking transport projects by their socioeconomic value or financial internal rate of return? Transport Policy, 12(2), p.131-136.

Council, F., Reinfurt, D., Compbell, B., Roediger, F., Carroll, C., Amitabh, D. and Dunham, J. (1980).Crash Research Manual.Publication FHWA/RD-80/016.FHWA, U.S. Department of Transportation.

Datta, T.K., Bowman, B.L., Opiela, K. S.(1978). Evaluation of Highway Safety Projects Using Quality Control Techniques.InTransportation Research Record: Journal of Transportation Research Board, No.672, National Research Council, Washington, D.C., pp. 9-16.

FHWA. (1981a). Highway Safety Evaluation: Procedural Guide. Report for the Federal Highway Safety Administration, Prepared by GoodellGrivas, Inc., Southfield, MI.

FHWA. (1981b). Highway Safety Improvement Program.Report for the Federal Highway Administration, Prepared by GoodellGrivas, Inc., Southfield, MI (FHWA-TS-81-218).

Grant, E.L., Ireson, W.G., and Lavenworth, R.S. (1990). Principles of Engineering Economy, John Wily and Sons, $8^{\text {th }}$ ed. New York. 
Harford, J.D.(2006). Congestion, pollution, and benefit-to-cost ratios of US public transit systems.Transportation Research Part D: Transport and Environment, 11(1), p.45-58.

Holz-Rau, C. \&Scheiner, J. (2011). Safety and travel time in cost-benefit analysis: A sensitivity analysis for North Rhine-Westphalia. Transport Policy, 18(2), p.336-346.

Hobday, M.B., and Knight, S. (2010). Motor vehicle collisions involving adult pedestrians in eThekwini in 2007.International Journal of Injury Control and Safety Promotion, 17(1), p.61-68.

Jorgenson, R. and Associates, (1977).(Associates), NCHRP Report 197, Cost and Safety Effectiveness of Highway Design Elements, National Research Council.

Khasnabis, S., Opiela, K.S., and Arbogast, R.G. (1982). Economic Evaluation of Development Projects along Transportation Right of Way”, Transportation Engineering Journal of the American Society of Civil Engineers, Vol. 108, TE 1,pp. 51-70.

Khasnabis, S., Naseer, M., Baig, M.F. and Opiela, K.S. (1999a). Roadside Safety Analysis Program As a Tool for Economic Evaluation of Roadside Safety Projects, Transportation Research Record: Journal of Transportation Research Board, No. 1690, TRB, National Research Council, Washington, D.C., pp. 31-41.

Khasnabis, S., Rudraraju, R.K. and Baig, M.F. (1999b). Economic Evaluation of Signal Preemption Projects, Transportation Engineering Journal of the American Society of Civil Engineers, Vol. 125, No. 2, pp. 160-167,.

Khasnabis, S., Safi, C., and Mishra, S. (2006). Safety Improvements for Urban Arterials. Final Report submitted to Michigan Department of Transportation. 
Khasnabis, S., Dhingra, S.L., Mishra, S., and Safi, C. (2010). Mechanisms for Transportation Infrastructure Investment in Developing Countries, Journal of Urban Planning and Development, American Society of Civil Engineers (ASCE), Vol.136, No. 1, pp. 94-103.

Laughland, J. C. (1975). NCHRP Report 162:Methods For Evaluation Highway Safety Improvements, National Research Council.

Li, Z. and Madanu, S. (2009). Highway Project Level Life-Cycle Benefit/Cost Analysis under Certainty, Risk, and Uncertainty: Methodology with Case Study. Journal of Transportation Engineering, 135, p.516.

Mak, K.K., Sicking, D.L., and Zimmerman, K. (1998).Roadside Safety Analysis Program: A Cost Effectiveness Analysis Procedure. In Transportation Research Record: Journal of Transportation Research Board, No. 1647,TRB, National Research Council, Washington, D.C., pp. 67-74.

NHTSA. (1977). The Evaluation of Highway Traffic Safety Programs.US Department of Transportation, National Highway Traffic Safety Administration (NHTSA).

NSC. (2004). Estimating the Costs of Unintentional Injuries, 2006, National Safety Council (NSC) Report.

Rotaris, L., Romeo, D., Edoardo, M., and Jerome, M. (2010). The urban road pricing scheme to curb pollution in Milan, Italy: Description, impacts and preliminary cost-benefit analysis assessment. Transportation Research Part A: Policy and Practice, 44(5), p.359-375.

Salling, K.B., and Banister, D. (2009). Assessment of large transport infrastructure projects: The CBA-DK model. Transportation Research Part A: Policy and Practice, 43(9-10), p.800813. 
USDOT. (1991). The Cost of Highway Crashes, Report for the Federal Highway Administration, Publication FHWA-RD-9-055. FHWA, U.S. Department of Transportation, McLean, VA. Vassallo, J.M. (2010). The role of the discount rate in tendering highway concessions under the LPVR approach.Transportation Research Part A: Policy and Practice, 44(10), p.806-814.

Winfrey, R. (1969). Economic Analysis for Highways.International Textbook Company, Scranton, Pennsylvania.

Winfrey, R. (1974). Traffic Crash Costs in Economic Analysis.Report for the Highway Users Federation for Safety and Mobility. 


\section{List of Tables}

1

2

3

4

5

6

7

8
Probable Causes and Suggested Countermeasures

Proposed Alternatives for Study Site

Analysis of Mutually Exclusive Alternatives Using the (C/E) Technique Analysis of Mutually Exclusive Alternatives Using the $(B / C)$ Technique Analysis of Mutually Exclusive Alternatives Using the (IRR) Technique Analysis of Mutually Exclusive Alternatives Using the (PP) Technique Analysis to Supplement Challenger Defender Technique

Decision Rules for Selecting Optimum Project for Mutually Exclusive Alternatives and Results of Case Study Application 
Table 1. Probable Causes and Suggested Countermeasures

\begin{tabular}{|l|l|}
\hline \multicolumn{1}{|c|}{ Probable Causes } & Suggested Countermeasures \\
\hline 1.No curbs on both Streets & 1. Curbs on Metro Parkway(Both Directions) \\
2.Too many driveway activities & 2. Median on driveway for avoiding conflict \\
3.Insufficient Lane Directions & 3.Sign as Right Turn Only \\
4.Heavy traffic on driveway around & 4. Divide M97 with raised median (prohibit left \\
intersection & turns) \\
5.Heavy right turn traffic from M97 to & 5. Close down multiple driveways and construct a \\
Metro & new driveway with signalized operation to the \\
6. Poor pavement condition & M97 \\
7. Poor Lighting at Intersection & 6. Improve Pavement condition \\
\hline
\end{tabular}


Table 2. Proposed Alternatives for Study Site

\begin{tabular}{|c|c|c|}
\hline $\begin{array}{l}\text { Improvement } \\
\text { Alternatives }\end{array}$ & Type of Alternatives & $\begin{array}{c}\text { Crash Reduction } \\
\text { Factor (CRF) } \\
\end{array}$ \\
\hline Alternative -1 & $\begin{array}{l}\text { 1. Install Proper Signs } \\
\text { 2. Improve Signal Timings }\end{array}$ & $\begin{array}{l}\text { CRF1 }=20 \% \\
\text { CRF2 }=8 \% \\
\text { Combined CRF } \\
=26.4 \%\end{array}$ \\
\hline Alternative - 2 & $\begin{array}{l}\text { 1. Close down multiple driveways and construct a new driveway } \\
\text { with signalized operation to the M97 } \\
\text { 2. Improve pavement condition } \\
\text { 3. Improve Signal Timings }\end{array}$ & $\begin{array}{l}\text { CRF1 }=10 \% \\
\text { CRF2 }=25 \% \\
\text { CRF3 }=8 \% \\
\text { Combined CRF } \\
=37.9 \%\end{array}$ \\
\hline Alternative -3 & $\begin{array}{l}\text { 1. Prohibit On Street Parking } \\
\text { 2. Improve Intersection Lighting } \\
\text { 3. Divide M97 with raised median near intersection (prohibit left } \\
\text { turns) } \\
\text { 4. Improve Signal Timing }\end{array}$ & $\begin{array}{l}\text { CRF1 }=30 \% \\
\text { CRF2 }=30 \% \\
\text { CRF3 }=30 \% \\
\text { CRF4 }=8 \% \\
\text { Combined CRF } \\
=63.93 \%\end{array}$ \\
\hline Alternative - 4 & $\begin{array}{l}\text { 1. Curbs On Metro Parkway } \\
\text { 2. Separate Entry And Exit Gates By Raised Median At } \\
\text { Driveways } \\
\text { 3. Divide M97 With Raised Median Near Intersection (Prohibit } \\
\text { Left Turns) } \\
\text { 4. Install Proper Signs } \\
\text { 5. Improve Signal Timings }\end{array}$ & 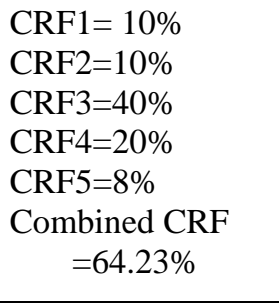 \\
\hline Alternative -5 & $\begin{array}{l}\text { 1. Curbs On Metro Parkway (Both Directions) } \\
\text { 2. Install Proper Signs } \\
\text { 3. Divide M97 With Raised Median (Prohibit Left Turns) } \\
\text { 4. Close Down Multiple Driveways And Construct A New } \\
\text { Driveway With Signalized Operation To The M97 } \\
\text { 5. Improve Pavement Condition } \\
\text { 6. Improve Signal Timings }\end{array}$ & $\begin{array}{l}\text { CRF1 }=10 \% \\
\text { CRF2 }=20 \% \\
\text { CRF3 }=40 \% \\
\text { CRF4 }=10 \% \\
\text { CRF5 }=25 \% \\
\text { CRF6 }=8 \% \\
\text { Combined CRF } \\
=73.17 \%\end{array}$ \\
\hline Alternative -6 & $\begin{array}{l}\text { 1. Install Roundabout } \\
\text { 2. Improve Pavement Condition } \\
\text { 3.Close Down Multiple Driveways And Construct New Opening } \\
\text { Away From Roundabout } \\
\text { 4. Install Proper Warning Signs }\end{array}$ & $\begin{array}{l}\text { CRF1 }=60 \% \\
\text { CRF2 }=25 \% \\
\text { CRF3 }=10 \% \\
\text { CRF4 }=10 \% \\
\text { CRF5 }=25 \% \\
\text { Combined CRF } \\
=81.77 \%\end{array}$ \\
\hline
\end{tabular}


Table 3. Analysis of Mutually Exclusive Alternatives Using the (C/E) Technique

\begin{tabular}{|l|c|c|c|c|c|c|}
\hline \multirow{2}{*}{\multicolumn{1}{|c|}{ Economic Analysis Data }} & \multicolumn{6}{|c|}{ Alternatives Listed in Increasing Order of } \\
\cline { 2 - 8 } & 1 & 2 & 3 & 4 & 5 & 6 \\
\hline 1.Initial Investment (\$1000) & 110 & 214 & 258 & 444 & 694 & 916 \\
\hline 2.Annual O\&M (\$1000) & 11.00 & 21.40 & 25.80 & 44.40 & 69.40 & 91.56 \\
\hline 3.Periodic O\&M (\$1000) @ n=3,6 \&9 & 33.00 & 64.20 & 77.40 & 133.20 & 208.20 & 274.68 \\
\hline 4.EUAC (\$1000/Yr) (Eqn. 2) & 35.53 & 69.13 & 83.34 & 143.42 & 224.18 & 295.76 \\
\hline $\begin{array}{l}\text { 5.Number of (Equivalent-Injury) Crashes } \\
\text { Saved Annually(N) }\end{array}$ & 12.67 & 18.19 & 30.69 & 30.83 & 35.12 & 39.25 \\
\hline 6.C/E Value (\$1000/Crash) & 2.80 & 3.80 & $2.72 *$ & 4.65 & 6.38 & 7.54 \\
\hline
\end{tabular}

*objective C: Alt3 
Table 4.Analysis of Mutually Exclusive Alternatives Using the (B/C) Technique

\begin{tabular}{|c|c|c|c|c|c|c|}
\hline \multirow{2}{*}{ Economic Analysis Data } & \multicolumn{6}{|c|}{ Alternatives Listed in Increasing Order of Investment } \\
\hline & 1 & 2 & 3 & 4 & 5 & 6 \\
\hline 1. Initial Investment (\$1000) & 110 & 214 & 258 & 444 & 694 & 916 \\
\hline 2. Annual O\&M (\$1000) & 11.00 & 21.40 & 25.80 & 44.40 & 69.40 & 91.56 \\
\hline 3. Periodic O\&M (\$1000)@ n=3,6 \&9 & 33.00 & 64.20 & 77.40 & 133.20 & 208.20 & 274.68 \\
\hline 4. EUAC $(\$ 1000 / Y r)$ & 35.53 & 69.13 & 83.34 & 143.42 & 224.18 & 295.76 \\
\hline 5. Crash Cost Savings Only, EUAB & 454.59 & 652.61 & 1100.93 & 1105.99 & 1259.93 & 1408.01 \\
\hline 6. (B/C) absolute (Crash Cost Savings) & $12.79 *$ & 9.44 & $13.21^{* * *}$ & 7.71 & 5.62 & $4.76^{* *}$ \\
\hline 7. (B/C) $)_{\text {absolute }} \geq 1.00$ ? & $\mathrm{Y}$ & $\mathrm{Y}$ & $\mathrm{Y}$ & $\mathrm{Y}$ & $\mathrm{Y}$ & $\mathrm{Y}$ \\
\hline 8. Compare with Defender & & 1 & 2 & 3 & 4 & 5 \\
\hline 9. Incremental EUAC $(\$ 1000 / Y r)$ & & 33.59 & 14.21 & 60.08 & 140.84 & 71.58 \\
\hline 10.Incremental Benefit EUAB $(\$ 1000 / Y r)$ & & 198.02 & 448.32 & 5.06 & 159.00 & 148.09 \\
\hline 11. $(\mathrm{B} / \mathrm{C})_{\text {marginal }}$ & & 5.89 & 31.54 & 0.08 & 1.09 & $2.07 * *$ \\
\hline 12. $(\mathrm{B} / \mathrm{C})_{\text {marginal }} \geq 1.00$ ? & & $\mathrm{Y}$ & $\mathrm{Y}$ & $\mathrm{N}$ & $\mathrm{Y}$ & $\mathrm{Y}$ \\
\hline 13. Defender & & 2 & 3 & 3 & 5 & 6 \\
\hline
\end{tabular}

*Objective A : Alt1, ${ }^{* *}$ Objective B: Alt6, ${ }^{* * *}$ Objective C: Alt3 
Table 5. Analysis of Mutually Exclusive Alternatives Using the (IRR) Technique

\begin{tabular}{|c|c|c|c|c|c|c|}
\hline \multirow{2}{*}{ Economic Analysis Data } & \multicolumn{6}{|c|}{ Alternatives Listed in Increasing Order of Investment } \\
\hline & 1 & 2 & 3 & 4 & 5 & 6 \\
\hline 1. Initial Investment (\$1000) & 110 & 214 & 258 & 444 & 694 & 916 \\
\hline 2.Annual O\&M (\$1000) & 11.00 & 21.40 & 25.80 & 44.40 & 69.40 & 91.56 \\
\hline $\begin{array}{l}\text { 3.Periodic O\&M (\$1000) @ } \\
n=3,6 \& 9\end{array}$ & 33.00 & 64.20 & 77.40 & 133.20 & 208.20 & 274.68 \\
\hline $\begin{array}{l}\text { 4. Crash Cost Savings Only, } \\
\text { EUAB }\end{array}$ & 454.59 & 652.61 & 1100.93 & 1105.99 & 1259.93 & 1408.01 \\
\hline 5. (IRR) $)_{\text {absolute }}$ & $343.86 \% *$ & $251.36 \%$ & $355.33 \% * * *$ & $203.49 \%$ & $145.33 \%$ & $121.27 \% * *$ \\
\hline $\begin{array}{l}\text { 6. (IRR) })_{\text {absolute }} \geq \text { MARR of } \\
6 \%\end{array}$ & $\mathrm{Y}$ & $\mathrm{Y}$ & $\mathrm{Y}$ & $\mathrm{Y}$ & $\mathrm{Y}$ & $\mathrm{Y}$ \\
\hline 7. Compare with Defender & & 1 & 2 & 3 & 4 & 5 \\
\hline 8. (IRR) $)_{\text {marginal }}(\%)$ & & $153 \%$ & $859 \%$ & $0 \%$ & $12 \%$ & $44 \% * *$ \\
\hline 9. $(\text { IRR })_{\text {marginal }} \geq$ MARR?? & & $\mathrm{Y}$ & $\mathrm{Y}$ & $\mathrm{N}$ & $\mathrm{Y}$ & $\mathrm{Y}$ \\
\hline 10. Defender & & 2 & 3 & 3 & 5 & 6 \\
\hline
\end{tabular}

* Objective A : Alt1, ${ }^{* *}$ Objective B: Alt6, ${ }^{* * *}$ Objective C: Alt3 
Table 6. Analysis of Mutually Exclusive Alternatives Using the (PP) Technique

\begin{tabular}{|c|c|c|c|c|c|c|}
\hline \multirow{2}{*}{ Economic Analysis Data } & \multicolumn{6}{|c|}{ Alternatives Listed in Increasing Order of Investment } \\
\hline & 1 & 2 & 3 & 4 & 5 & 6 \\
\hline 1. Initial Investment (\$1000) & 110 & 214 & 258 & 444 & 694 & 916 \\
\hline 2. Annual O\&M (\$1000) & 11.00 & 21.40 & 25.80 & 44.40 & 69.40 & 91.56 \\
\hline $\begin{array}{l}\text { 3. Periodic O\&M (\$1000) @ n=3,6 } \\
\text { \&9 }\end{array}$ & 33.00 & 64.20 & 77.40 & 133.20 & 208.20 & 274.68 \\
\hline 4. EUAC $(\$ 1000 / Y r)$ & 35.53 & 69.13 & 83.34 & 143.42 & 224.18 & 295.76 \\
\hline 5. Crash Cost Savings Only, EUAB & 454.59 & 652.61 & 1100.93 & 1105.99 & 1259.93 & 1408.01 \\
\hline 6. (PP) absolute @ i=6\% & $0.24 *$ & 0.30 & $0.23^{* * *}$ & 0.34 & 0.42 & $0.47 * *$ \\
\hline 7. (PP) $)_{\text {absolute }} \leq 10$ (yrs.) & $\mathrm{Y}$ & $\mathrm{Y}$ & $\mathrm{Y}$ & $\mathrm{Y}$ & $\mathrm{Y}$ & $\mathrm{Y}$ \\
\hline 8. Compare with Defender & & 1 & 2 & 3 & 4 & 5 \\
\hline 9. Incremental EUAC $(\$ 1000 / Y r)$ & & 33.59 & 14.21 & 60.08 & 140.84 & 71.58 \\
\hline $\begin{array}{l}\text { 10.Incremental Benefit EUAB } \\
(\$ 1000 / Y r)\end{array}$ & & 198.02 & 448.32 & 5.06 & 159.00 & 148.09 \\
\hline 11. (PP) $)_{\text {marginal }} @ \mathrm{i}=6 \%$ (yrs. ) & & 0.66 & 0.12 & - & 6.50 & $2.20 * *$ \\
\hline 12. $(\mathrm{PP})_{\text {marginal }} \leq 10(\mathrm{yrs})$. & & $\mathrm{Y}$ & $\mathrm{Y}$ & $\mathrm{N}$ & $\mathrm{Y}$ & $\mathrm{Y}$ \\
\hline 13. Defender & & 2 & 3 & 3 & 5 & 6 \\
\hline
\end{tabular}

*bjective A : Alt1, ${ }^{* *}$ Objective B:Alt6, ${ }^{* * *}$ Objective C: Alt3 
Table 7.Analysis to Supplement Challenger Defender Technique

\begin{tabular}{|l|c|c|c|c|c|c|}
\hline \multirow{2}{*}{ Economic Analysis Data } & \multicolumn{6}{|c|}{ Alternatives Listed in Increasing Order of Investment } \\
\cline { 2 - 8 } & 1 & 2 & 3 & 4 & 5 & 6 \\
\hline 1. PWOC of Investment Cost $(\$ 1000)$ & 261.5 & 508.8 & 613.4 & 1055.6 & 1650 & 2176.8 \\
\hline 2. Excess Capital $(\$ 1000)$ & 1915.3 & 1668 & 1563.4 & 1123.2 & 528.8 & 0 \\
\hline $\begin{array}{l}\text { 3. Annual Earnings from Excess Capital } \\
\text { (\$1000) }\end{array}$ & 260.2 & 226.6 & 212.4 & 152.6 & 71.8 & 0 \\
\hline 4. EUAB $(\$ 1000)$ & 454.59 & 652.61 & 1100.93 & 1105.99 & 1259.93 & 1408.01 \\
\hline 5. Total Earnings (\$1000) & 714.8 & 879.2 & 1313.3 & 1258.6 & 1331.7 & 1408 \\
\hline
\end{tabular}


Table 8. Decision Rules for Selecting Optimum Project for Mutually Exclusive Alternatives and Results of Case Study Application

\begin{tabular}{|c|c|c|c|}
\hline $\begin{array}{c}\text { Analytic } \\
\text { Technique }\end{array}$ & $\begin{array}{c}\text { Objective A (Constrained } \\
\text { Resource) }\end{array}$ & Objective B (Investment) & Objective C (Face Value) \\
\hline C/E Technique & NA & NA & $\begin{array}{c}\text { Select the alternative with } \\
\text { the least C/E Index } \\
\text { Select Alternative } 3\end{array}$ \\
\hline $\begin{array}{l}\text { Benefit Cost } \\
\text { (B/C) Ratio } \\
\text { Technique }\end{array}$ & $\begin{array}{l}\text { Select the least expensive } \\
\text { alternative subject to: } \\
\text { (B/C })_{\text {absolute }} \geq 1.00 \\
\text { Select Alternative } 1\end{array}$ & $\begin{array}{l}\text { Select the most expensive } \\
\text { alternative subject to: } \\
\text { (B/C) })_{\text {absolute }} \geq 1.0 \\
(\mathrm{~B} / \mathrm{C})_{\text {marginal }} \geq 1.00 \\
\text { Select Alternative } 6\end{array}$ & $\begin{array}{l}\text { Select the alternative with } \\
\text { highest }(B / C)_{a b s o l u t e} \text { subject } \\
\text { to: } \\
(\mathrm{B} / \mathrm{C})_{\text {absolute }} \geq 1.00 \\
\text { Select Alternative } 3\end{array}$ \\
\hline \begin{tabular}{|} 
Internal Rate of \\
Return (IRR) \\
Technique
\end{tabular} & $\begin{array}{l}\text { Select the least expensive } \\
\text { alternative subject to: } \\
\text { (IRR) })_{\text {absolute }} \geq \text { MARR } \\
\text { Select Alternative } 1\end{array}$ & $\begin{array}{l}\text { Select the most expensive } \\
\text { alternative subject to: } \\
\text { (IRR) })_{\text {absolute }} \geq \text { MARR } \\
\text { (IRR) } \text { marginal } \geq \text { MARR } \\
\text { Select Alternative } 6\end{array}$ & $\begin{array}{c}\text { Select the alternative with } \\
\text { highest (IRR) } \\
\text { subject to: } \\
\text { (IRR) })_{\text {absolute }} \geq \text { MARR } \\
\text { Select Alternative } 3\end{array}$ \\
\hline $\begin{array}{l}\text { Pay off Period } \\
\text { (PP) Technique }\end{array}$ & $\begin{array}{l}\text { Select the least expensive } \\
\text { alternative subject to: } \\
\quad\left(\mathrm{n}_{1}\right)_{\text {absolute }} \leq \mathrm{n} \\
\text { Select Alternative } 1\end{array}$ & $\begin{array}{l}\text { Select the most expensive } \\
\text { alternative subject to: } \\
\left(\mathrm{n}_{1}\right)_{\text {absolute }} \leq \mathrm{n} \\
\left(\mathrm{n}_{1}\right)_{\text {marginal }} \leq \mathrm{n} \\
\text { Select Alternative } 6\end{array}$ & $\begin{array}{c}\text { Select the alternative with } \\
\text { the least }\left(n_{1}\right)_{\text {absolute }} \text { value } \\
\text { subject to : } \\
\left(\mathrm{n}_{1}\right)_{\text {absolute }} \leq \mathrm{n} \\
\text { Select Alternative } 3\end{array}$ \\
\hline
\end{tabular}

